\section{Preconditioned Endothelial Progenitor Cells as Biomarker of Vascular Reparation?}

\section{Abstract}

The endothelial progenitor cells (EPCs) have defined as cells positively labeled with both hematopoietic stem cells (CD34) and endothelial cell markers predominantly VEGF receptor-2 (VEGFR2) cumulatively. Therefore, there are at least two types of EPCs labelled as early outgrowth EPCs and late outgrowth EPCs probably distinguished their vascular protective ability. Recent animal and clinical studies have shown that reduced number and weak function of EPCs may not only indicate to higher CV risk, but contribute to the impaired heart and vessels reparation. Interestingly, there are some subpopulations of EPCs especially recruited from peripheral blood cells, which may exhibit very variable pro-angiogenic effect and endothelial repair capacity and they are called "preconditioned" EPCs. The aim of the short commentary is depicted the possibilities to use of measurement of traditionally labeled EPCs as biomarker of cardiovascular risk.

Keywords: Cardiovascular disease; Precondition; Endothelial progenitor cells, Vascular complications; Angiogenesis; Reparation

\section{Berezin AE}

\author{
Therapeutic Unit, Private Hospital "Vita \\ Center", 3, Sedova str, Zaporozhye \\ and Consultant of Therapeutic Unit, \\ Internal Medicine Department, State \\ Medical University, 26, Mayakovsky av, \\ Zaporozhye, Ukraine
}

Corresponding author:

Dr. Alexander E Berezin

\section{$\risingdotseq$ aeberezin@gmail.com \\ dr_berezin@mail.ru}

Consultant of Therapeutic Unit, Private Hospital "Vita Center", 3, Sedova str, Zaporozhye, and Consultant of Therapeutic Unit, Internal Medicine Department, State Medical University, 26, Mayakovsky av, Zaporozhye, Ukraine

\section{Tel: +380612894585}

Received: January 10, 2017; Accepted: February 24, 2017; Published: February 27, 2017

\section{Introduction}

Citation: Berezin AE. Preconditioned Endothelial Progenitor Cells as Biomarker of Vascular Reparation? Insights in Biomed. 2017, $2: 1$.

Endothelial progenitor cells (EPCS) have determined primitive cells originated from precursors found in the bone marrow and peripheral blood [1]. The ability of EPCs for self-renewal and differentiation into mature endothelial cells has recently been under intense investigation [2] and remains of high interest for regenerative medicine [3]. The recent pre-clinical and clinical studies have shown a key role of bone marrow EPCs in the endothelial repair, angiogenesis, neovascularization and attenuation of vascular function, whereas EPCs derived from peripheral blood cells including circulating mononuclears are under tight epigenetic control, and several paracrine and metabolic mechanisms and they are considered a central mechanism of immediate reparative response of injury [4-6]. There is a large body of evidence regarding that the both subpopulations of EPCs are mobilized or released into systemic circulation in response to specific stimuli [7-9].

Formerly EPCs were defined as cells positively labeled with both hematopoietic stem cells (CD34) and endothelial cell markers predominantly VEGF receptor-2 (VEGFR2) cumulatively [1]. Later an expression of other hematopoietic stem cells markers (CD133, AC133) and some endothelial markers (platelet-endothelial cell adhesion molecule known as CD31, VE-cadherin also known as CD 144, caveolin-1, von Willebrand factor, and endothelial NO synthase) on the surface of EPCs was found [10-13]. Therefore, some subsets of EPCs may express mononuclear antigens, i.e., CD14, CD11b, CD11c, together with CD34 or VEGFR2, CD45, Tei2 and Flt-1 [14] and shape so called "non-classical" phenotypes. All these EPCs remain vascular protective capacity and may differentiate into mature endothelial cells under effect of microenvironment, paracrine regulators and appropriate growth factors (e.g., VEGF, fibroblast growth factor).

Additionally, there are at least two types of EPCs labelled as early outgrowth EPCs and late outgrowth EPCs and isolated from similar source [15]. Both subpopulations of EPCs have expressed CD144, Flt-1, KDR (VEGFR2), and CD45 markers in different manner. Late outgrowths EPCs produced more nitric oxide, incorporated more into human umbilical vein ECs monolayer, and are able to better form capillary tube than early EPC [16]. Early EPC secreted more pro-angiogenic cytokines (VEGF and interleukin-8) than late EPC at culture [17]. Moreover, early EPCs intervened in the monolayer of human umbilical vein endothelial 
cells (HUVEC), but more late EPCs were incorporated to HUVEC [18]. Overall both subpopulations of EPC might distinguish one another in ability to differentiate into circulating angiogenic cells (referred as early EPCs), shaping endothelial colony cells (referred as late outgrowth EPCs), and inducing vasculogenesis [19].

Whether early and late outgrowth EPCs mediate similar effect on vascular protection and tissue repair is uncertain [20]. There is large evidence that the EPCs especially recruited from peripheral blood cells may exhibit very variable pro-angiogenic effect and endothelial repair capacity and they are called "preconditioned". Indeed, pro-inflammatory cytokines realizing into circulation from mononuclear cells following direct vascular endothelial injury after stenting and angioplasty procedures via NO/cGMP/p38 MAPK and Notch4 signaling pathways are involved in precondition of wild-type EPCs and increase an ability of EPCs to neointima formation [21,22]. In contrast, some metabolites, i.e., creatinine, phosphates, glucose, and cytokines (interleukin [IL]-2beta, IL-8, tumor necrosis factor-alpha) negatively reprogram the early EPCs suppressing their maturation and leading to weak differentiation into mature endothelial cells [23-26]. Finally, growth dynamics, lipoprotein transport, and gene expression of EPCs are actively modified by secretomes of different cells involving in the pathogenesis of cardiovascular (CV) and metabolic disease.

All these claim a fact that not only a lower level of circulating EPCs, but reduced EPC functionality are powerful factor of increased CV risk [27-30]. Indeed, recent animal and clinical studies have shown that reduced number and weak function of EPCs may not only indicate to higher CV risk, but contribute to the impaired heart and vessels reparation [31-33]. In a way it has suggested that impaired differentiation, proliferation and migration of EPCS as well as exhaustion of endogenous endothelial repair mechanisms involving EPCS may contribute to vascular dysfunction, inflammation, thrombosis and impairing and fibrinolysis and re- endothelialisation. Consequently, CV risk factors may influence on EPC morphology and function shaping impaired secretory phenotype and altered expression of regulatory factors [34]. On the one hand, all these mediate inadequate response of endothelial repair system toward vascular injury. On the other hand, preconditioned by CV risk factors EPC are discussed a main modulator of vascular reparation and restoring endothelial functions [35].

\section{Discussion}

In this context, measurement of circulating preconditioned EPCs' level might be much more pretty accurate biomarker of CV risk and CV outcomes in various diseases. Consequently, a simple measurement of circulating EPC number showing potential for improved endothelial function based on labeling of specific antigens might be wrong step to determine the regenerative ability of EPCS. Probably, we have precious many investigations with controversial results regarding predictive role of EPC count in peripheral blood in CV disease and diabetes [36-41]. However, lack of accessible and affordable approved methods regarding an assay of ability to survive, moving, differentiation, and colony forming of preconditioned EPCS is challenge for use of this approach in routine clinical practice, although there are data that the even simple measurement of EPCs in circulation might be useful for CV risk predicting in patients with acute coronary syndrome, atherosclerosis, heart failure and diabetes $[42,43]$.

\section{Conclusion}

Large clinical studies are required to re-assay the role of circulation EPC number measurement in CV risk prediction. Probably, novel methods regarding exam of functionality preconditioned EPCS are needed in future. 


\section{References}

1 Asahara T, Murohara T, Sullivan A, Silver M, Van der Zee R, et al. (1997) Isolation of putative progenitor endothelial cells for angiogenesis. Science 275: 964-967.

2 Asahara T (2007) Endothelial progenitor cells for vascular medicine. Yakugaku Zasshi 127(5): 841-845.

3 Abe Y, Ozaki Y, Kasuya J, Yamamoto K, Ando J, et al. (2013) Endothelial progenitor cells promote directional three-dimensional endothelial network formation by secreting vascular endothelial growth factor. PLoS One 8(12): e82085.

4 Berezin A (2016) Impaired immune phenotype of endothelial cellderived microparticles: the missed link between diabetes-related states and cardiovascular complications? Journal of Data Mining in Genomics \& Proteomics 7(2): 195-197.

5 Cai H, Harrison DG (2000) Endothelial dysfunction in cardiovascular diseases: The role of oxidant stress. Circ Res 87: 840-844.

6 Ogita H, Liao J (2004) Endothelial function and oxidative stress. Endothelium 44: 248-252.

7 Berezin A (2016) Metabolic memory phenomenon in diabetes mellitus: achieving and perspectives. Diabetes and Metabolic Syndrome: Clinical Research \& Reviews.

8 Berezin AE, Kremzer AA, Martovitskaya YV, Samura TA, Berezina TA (2014) Serum uric acid predicts declining of circulating proangiogenic mononuclear progenitor cells in chronic heart failure patients. J Cardiovasc Thorac Res 6(3): 153-162.

9 Berezin AE, Kremzer AA (2014) Circulating endothelial progenitor cells as markers for severity of ischemic chronic heart failure. J Card Fail 20(6): 438-447.

10 Peichev M, Naiyer AJ, Pereira D, Zhu Z, Lane WJ, et al. (2000) Expression of VEGFR-2 and AC133 by circulating human CD34(+) cells identifies a population of functional endothelial precursors. Blood 95: 952-958.

11 Yin AH, Miraglia S, Zanjani ED, Almeida-Porada G, Ogawa M, et al. (1997) AC133, a novel marker for human hematopoietic stem and progenitor cells. Blood 90: 5002-5012.

12 Civin Cl, Banquerigo ML, Strass LC, Loken MR (1987) Antigenic analysis of hematopoiesis. VI. Flow cytometric characterization of My-10 positive progenitor cells in normal human bone marrow. Exp Hematol 15: 10-17.

13 Romagnani P, Annunziato F, Liotta F, Lazzeri E, Mazzinghi B, et al. (2005) CD14+CD34 low cells with stem cell phenotypic and functional features are the major source of circulating endothelial progenitors. Circ Res 97: 314-322.

14 Leri A, Kajstura J (2005) Endothelial progenitor cells: Unexpected disclosures. Circ Res 97(4): 299-301.

15 Hur J, Yoon CH, Kim HS, Choi JH, Kang HJ, et al. (2004) Characterization of two types of endothelial progenitor cells and their different contributions to neovasculogenesis. Arterioscler Thromb Vasc Biol 24: 288-293.

16 Lin Y, Weisdorf DJ, Solovey A, Hebbel RP (2000) Origins of circulating endothelial cells and endothelial outgrowth from blood. J Clin Invest 105: 71-77.

17 Schmeisser A, Garlichs CD, Zhang H, Eskafi S, Graffy C, et al. (2001) Monocytes coexpress endothelial and macrophagocytic lineage markers and form cord-like structures in Matrigel under angiogenic conditions. Cardiovasc Res 49(3): 671-680.
18 Vaughan EE, O'Brien T (2012) Isolation of circulating angiogenic cells. Methods Mol Biol 916: 351-356.

19 Friedrich EB, Walenta K, Scharlau J, Nickenig G, Werner N (2006) CD34-/CD133+/VEGFR-2+ endothelial progenitor cell subpopulation with potent vasoregenerative capacities. Circ Res 98: e20-e25.

20 Fadini GP, Avogaro A (2010) Potential manipulation of endothelial progenitor cells in diabetes and its complications. Diabetes Obes Metab 12(7): 570-583.

21 Liu NM, Siu KL, Youn JY, Cai H (2016) Attenuation of neointimal formation with netrin-1 and netrin-1 preconditioned endothelial progenitor cells. J Mol Med.

22 Lin CJ, Wu CJ, Wu PC, Pan CF, Wang TJ, et al. (2016) Indoxyl sulfate impairs endothelial progenitor cells and might contribute to vascular dysfunction in patients with chronic kidney disease. Kidney Blood Press Res 41(6): 1025-1036.

23 Berezin AE, Kremzer AA (2015) The impact of low-grading inflammation on circulating endothelial-derived progenitor cells in patients with metabolic syndrome and diabetes mellitus. Journal of Endocrinology and Diabetes 2 (3): 8-16.

24 Fadini GP, Sartore S, Agostini C, Avogaro A (2007) Significance of endothelial progenitor cells in subjects with diabetes. Diabetes Care 30: $1305-1313$

25 Fadini GP, De Kreutzenberg SV, Coracina A, Baesso I, Agostini C, et al. (2006) Circulating CD34+ cells, metabolic syndrome, and cardiovascular risk. Eur Heart J 27: 2247-2255.

26 Prisco AR, Hoffmann BR, Kaczorowski CC, McDermott-Roe C, Stodola TJ, et al. (2016) Tumor necrosis factor $\alpha$ regulates endothelial progenitor cell migration via CADM1 and NF-kB. Stem Cells 34(7): 1922-1933.

27 Sen S, McDonald SP, Coates PT, Bonder CS (2011) Endothelial progenitor cells: novel biomarker and promising cell therapy for cardiovascular disease. Clin Sci 120(7): 263-283.

28 Berezin A, Kremzer A, Berezina T, Martovotskaya Yu, Gromenko O (2016) Pattern of endothelial progenitor cells and apoptotic endothelial cell-derived microparticles in chronic heart failure patients with preserved and reduced left ventricular ejection fraction. EBio Medicine 4: 86-94.

29 Deschaseaux F, Selmani Z, Falcoz PE, Mersin N, Meneveau N, et al. (2007) Two types of circulating endothelial progenitor cells in patients receiving long term therapy by HMG-CoA reductase inhibitors. Eur J Pharmacol 562(1-2): 111-118.

30 Rockmaaker MB, Vergeer M, Van Zonneveld Aj, Rabelink TJ, Verhaar MC (2003) Endothelial progenitor cells mainly derived from the monocyte/macrophage containing CD34- but also partly derived from the hematopoetic stem cell containing $\mathrm{CD} 34+$ mononuclear population. Circulation 108: 150e.

31 Pearson MJ, Smart NA (2016) Effect of exercise training on endothelial function in heart failure patients: A systematic review meta-analysis. Int J Cardiol.

32 Kalender G, Kornberger A, Lisy M, Beiras-Fernandez A, Stock UA (2016) Kinetics of circulating endothelial progenitor cells in patients undergoing carotid artery surgery. Ther Clin Risk Manag 12: 1841 1847.

33 Yang SW, Hennessy RR, Khosla S, Lennon R, Loeffler D, et al. (2017) Circulating osteogenic endothelial progenitor cell counts: new biomarker for the severity of coronary artery disease. Int J Cardiol 227: 833-839. 
34 Guo Y, Ledesma RA, Peng R, Liu Q, Xu D (2017) The beneficial effects of cardiac rehabilitation on the function and levels of endothelial progenitor cells. Heart Lung Circ 26(1): 10-17.

35 Berezin AE. (2010) Biological markers of cardiovascular diseases. Part 3. In: Diagnostic and prognostic value of biological markers in stratification of patient $s$ with cardiometabolic risk. Lambert Academic Publishing GmbH, Moscow, Russsia.

36 Urbich C, Heeschen C, Aisher A, Dernbach E, Zeiher AM, et al. (2003) Relevance of monocytic features for neovascularization capacity of circulating endothelial progenitor cells. Circulation 108: 2511-2516.

37 Monge M, Massy ZA, Van Zonneveld AJ, Rabelink TJ (2011) Endothelial progenitor cells: What are we talking about? Nephrol Ther 7(7): 521-525.

38 Fadini GP, Agostini C, Avogaro A (2005) Endothelial progenitor cells and vascular biology in diabetes mellitus: current knowledge and future perspectives. Curr Diabetes Rev 1(1): 41-58.

39 Fadini GP, Sartore S, Albiero M, Baesso I, Murphy E, et al. (2006)
Number and function of endothelial progenitor cells as a marker of severity for diabetic vasculopathy. Arterioscler Thromb Vasc Biol 26: 2140-2146.

40 Kränkel N, Adams V, Linke A, Gielen S, Erbs S, et al. (2005) Hyperglycemia reduces survival and impairs function of circulating blood-derived progenitor cells. Arterioscler Thromb Vasc Biol 25(4): 698-703.

41 Ye L, Poh KK (2015) Enhancing endothelial progenitor cell for clinical use. World J Stem Cells 7(6): 894-898.

42 Berezin A, Samura T, Kremzer A, Berezina T, Martovitskaya $Y$, et al. (2016) An association of serum vistafin level and number of circulating endothelial progenitor cells in type 2 diabetes mellitus patients. Diabetes and Metabolic Syndrome: Clinical Research \& Reviews.

43 Werner N, Kosiol S, Schiegl T, Ahlers P, Walenta K, et al. (2005) Circulating endothelial progenitor cells and cardiovascular outcomes. N Engl J Med 353(10): 999-1007. 